${ }^{3}$ Godden DJ, Crompton GK. An objective assessment of the tube spacer in patients unable to use a conventional pressurised aerosol efficiently. Br F Dis Chest $1981 ; 75: 165-8$

${ }^{4}$ Newman SP, Moren F, Pavia D, Little F, Clzrke SW. Deposition of pressurised suspension aerosols inhaled through extension devices. Am Rev Resp Dis 1981;124:317-20.

${ }^{5}$ Williams SJ, Winner SJ, Clark TJH. Comparison of inhaled and intravenous terbutaline in acute severe asthma. Thorax $1981 ; 36: 629-31$.

(Accepted 28 May 1982)

Stoke Mandeville Hospital, Aylesbury, Bucks HP21 8AL

M D L MORGAN, MB, MRCP, registrar

B V SINGH, MB, BS, senior house officer

M H FRAME, PHD, clinical scientist, Astra clinical research unit

S J WILLIAMS, MB, MRCP, consultant physician

\section{Antihypertensive treatment with beta-blockers in patients aged over 65}

The use of beta-blockers in elderly patients with hypertension has been questioned owing to the increased incidence of heart failure in this age group. As our clinical impression at the outpatient hypertension clinic was that beta-blockers were well tolerated by elderly patients, ${ }^{1}$ we decided to analyse the use and tolerability of betablockers in all patients over 65 who were being treated with these drugs, with special reference to the occurrence of heart failure.

\section{Patients, methods, and results}

A total of 301 patients aged over 65 years were being treated at the clinic. Two hundred and seventeen of these were aged from 65 to 69,58 from 70 to 74 , and 26 over 75 .

Each year the doctors complete a computer record form for each patient with standardised questions about the case history, current antihypertensive treatment, side effects, and reasons for changes in treatment. Dyspnoea on exertion was diagnosed as heart failure if treatment with diuretics or digitalis was indicated.

Analysis of the prescription of beta-blockers in the different groups showed that three-quarters of the patients from 65 to 74 years and half of those aged over 75 were receiving beta-blockade. Analysis of the total treatment showed that $42(14 \%)$ were receiving beta-blockers alone, $51(17 \%)$ were receiving diuretics alone, and $193(64 \%)$ were receiving combined treatment with beta-blockers and diuretics or other drug combinations; $15(5 \%)$ were receiving no treatment. The mean dose for the two most commonly used beta-blockers was $189 \mathrm{mg} /$ day for the beta ${ }_{1}$-selective metoprolol and $252 \mathrm{mg} /$ day for the non-selective propranolol.

Analysis of the blood pressures showed good pressure control of 156/91 $\mathrm{mm} \mathrm{Hg}$ in those aged $65-69,166 / 94 \mathrm{~mm} \mathrm{Hg}$ in those aged $70-74$, and $174 / 93$ $\mathrm{mm} \mathrm{Hg}$ in those aged over 75 .

Changes of the beta-blocker medication fell into three groups: discontinuation (21 patients $(10 \%)$ ), reduction of the dose (12 patients $(5.5 \%)$ ) and change to another type (49 patients $(22.5 \%)$ ) - for example, from a non-

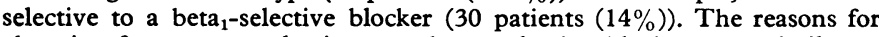

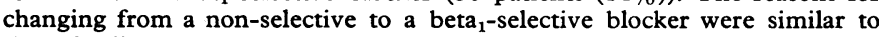
those leading to withdrawal of beta-blockade (see table).

Heart failure was diagnosed in 23 patients, of whom $16(70 \%)$ were on beta-blockade in combination with diuretics, digitalis, or both.

\section{Reason for withdrawal of beta-blockers}

\begin{tabular}{lcc}
\hline & No & $\%$ \\
\hline Sleep disturbances & 1 & 0.5 \\
Gastrointestinal symptoms & 2 & $1 \cdot 0$ \\
Obstructive lung disease and/or dyspnoea & 3 & $1 \cdot 4$ \\
Tiredness & 2 & 1.0 \\
Exanthema & 2 & $1 \cdot 0$ \\
Cold hands or feet & 1 & 0.5 \\
Bradycardia & 3 & $1 \cdot 4$ \\
Heart failure (without digitalis)* & 1 & 0.5 \\
Heart failure (on digitalis) & 1 & 0.5 \\
Diabetes mellitus & 1 & 0.5 \\
Reason not stated & 4 & $1 \cdot 8$ \\
\hline Total & 21 & $9 \cdot 7$ \\
\hline
\end{tabular}

* Treatment with a beta ${ }_{1}$-selective blocker was resumed after giving the patient digitalis.

\section{Comments}

This analysis showed that the beta-blockers were generally well tolerated in hypertensive patients over 65 . The side effects and patterns of dosage resembled those seen in younger age groups. Heart failure was the reason for discontinuing the treatment in only one patient. Most of the side effects could be overcome by changing from a non-

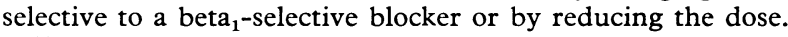

Heart failure was diagnosed in 23 patients $(11 \%)$ and of these patients $16(70 \%)$ were receiving beta-blockade in combination with diuretics or digitalis. In many of these patients symptoms of heart failure might have been due not to bad systolic contraction but to poor filling in stiff hearts. Even at heart rates as low as 120 beats/min the filling time becomes critical to the elderly heart. ${ }^{2}$ If the heart rate falls from 100 to 70 beats/min the diastolic filling time increases by $100 \%$ without the ejection time being affected. ${ }^{3}$ This favourable effect of beta-blockers on the diastolic filling is probably particularly important in the aged, stiff, hypertensive heart.

Beta-blockers have been claimed to reduce the incidence of coronary heart disease. ${ }^{4}$ If good efficacy and tolerance is achieved with betablockers alone or in combination with other drugs in elderly patients with hypertension this could be important since the incidence of coronary heart disease is increasing with age in both men and women and since coronary heart disease is the most common end-point in hypertension. ${ }^{5}$

1 Andersson $\mathrm{O}$, Berglund G, Hansson L, et al. Organisation and efficacy of an outpatient hypertension clinic. Acta Med Scand 1978;203:391-8.

${ }^{2}$ Harrison TR, Dixon K, Russel RO Jr, Bidwai PS, Coleman HN. The relation of age to the duration of contraction, ejection, and relaxation of the normal human heart. Am Heart $\mathcal{F}$ 1964;67:189-99.

${ }^{3}$ Rothe CF. Cardiodynamics. In: Selkurt EE, ed. Physiology. 4th ed. Boston: Little, Brown and Co, 1976:338.

4 Dollery CT. Does it matter how blood pressure is reduced? Clin Sci $1981 ; 61: 413-20$.

${ }^{5}$ Berglund G, Sannerstedt R, Andersson P, et al. Coronary heart-disease after treatment of hypertension. Lancet 1978;i:1-5.

(Accepted 11 fune 1982)

Outpatient Hypertension Clinic, Department of Medicine I,

Sahlgrenska Hospital, University of Göteburg, Sweden

JOHN WIKSTRAND, MD, associate professor of clinical physiology

GÖRAN BERGLUND, MD, associate professor of medicine

\section{High plasma calcitonin concentrations in chronic bronchitis}

Studies of extrathyroidal and extraultimobranchial production of calcitonin showed calcitonin-like immunoreactivity in brain and lung of lizards and pigeons. ${ }^{1}$ Immunofluorescence studies and electron microscopy of lizard lung showed secretory granules of calcitoninlike material in what were apparently Kulchitsky cells. ${ }^{2}$ Other workers had found Kulchitsky cells in human bronchial and bronchiolar epithelium and had also isolated calcitonin-like material from human lung. ${ }^{3}$

In chronic bronchitis the acini of mucous glands contain increased numbers of mucus-secreting cells. If Kulchitsky cells were similarly increased patients with chronic bronchitis might be expected to have raised circulating calcitonin concentrations. To test this hypothesis we measured plasma calcitonin concentrations in patients with mucopurulent disease and in a group of healthy, non-smoking controls. We also looked to see if there was some correlation between the plasma calcitonin concentrations and the cumulative numbers of cigarettes smoked during life.

\section{Subjects, methods, and results}

The study group comprised 45 men aged 36-78 years (mean 58.9) with chronic mucopurulent bronchitis. ${ }^{4}$ All were smokers or ex-smokers of cigarettes. Measurements were made during a quiescent phase of their illness when they were clear of acute infection and had stable blood gas values. None was taking any medication. Twelve healthy men aged $29-76$ years (mean 55.0 years) who had never smoked served as controls. 